\title{
Mechanical Properties of SiC long Fibre reinforced Copper
}

*A. Brendel, V. Paffenholz, Th. Köck, H. Bolt

Max-Planck-Institut für Plasmaphysik, EURATOM Association, Boltzmannstraße 2,

D-85748 Garching, Germany

*Corresponding author: Dr. Annegret Brendel

Phone: +49 8932 99-25 44

Fax: +498932 99-12 12

Annegret.Brendel@ipp.mpg.de 


\title{
Mechanical Properties of SiC long Fibre reinforced Copper
}

\author{
A. Brendel, V. Paffenholz, Th. Köck, H. Bolt \\ Max-Planck-Institut für Plasmaphysik, EURATOM Association, Boltzmannstraße 2, \\ D-85748 Garching, Germany
}

\begin{abstract}
$\mathrm{SiC}$ fibre reinforced copper is a potential novel heat sink material for the divertor of future fusion reactors to reinforce the zone between plasma facing material (W) and heat sink material ( $\mathrm{CuCrZr}$ ). The metal matrix composite (MMC) should be able to withstand heat loads up to $15 \mathrm{MW} / \mathrm{m}^{2}$ at operating temperatures of up to $550^{\circ} \mathrm{C}$.

SCS6 fibres were coated by magnetron sputtering with a titanium interlayer and the copper matrix was deposited by electroplating. The composite was consolidated by hotisostatic pressing. The average ultimate tensile strength of composite samples with $20 \%$ fibre reinforcement is $640 \mathrm{MPa}$ and for the Young's modulus $162 \mathrm{GPa}$ was determined. The Young's modulus decreases with increasing temperature and reaches $113 \mathrm{GPa}$ at $550^{\circ} \mathrm{C}$.
\end{abstract}

Fracture area analysis after tensile tests show the failure of the SCS 6 fibres at the interface between the two outer carbon layers. Titanium as interlayer led to an improved bonding between the outer carbon coating of the $\mathrm{SiC}$ fibres and the copper matrix.

\section{Introduction}

$\mathrm{SiC}$ fibre reinforced copper is a potential novel heat sink material for the divertor of future fusion reactors [1], to be used where high stresses occur at the interface between 
plasma facing material $(\mathrm{W})$ and heat sink material $(\mathrm{CuCrZr})$. It can be used under extreme conditions, where conventional homogeneous heat sink materials fail. The metal matrix composite (MMC) should be able to withstand heat loads of up to 15 $\mathrm{MW} / \mathrm{m}^{2}$ at operating temperatures of up to $550^{\circ} \mathrm{C}$ [2]. This becomes possible since the MMC combines the high thermal conductivity of copper $(380 \mathrm{~W} / \mathrm{mK})$ with the very high strength of the SCS6 fibre (at least $3450 \mathrm{MPa}$ ) [3]. For an improved bonding between the SCS6 fibre with its carbon enriched surface [4] and the copper matrix an interlayer is necessary, since copper does not adhere to carbon. A suitable choice is a thin titanium interlayer $(100 \mathrm{~nm})$ [5]. Ti reacts with the carbon layer of the SCS6 fibre to $\mathrm{TiC}$ [6] and forms the $\mathrm{Cu}_{4} \mathrm{Ti}$ alloy with the copper matrix [7]. Both reactions lead to chemical and mechanical bonding between SCS6 fibre and copper.

\section{Experimental}

SCS6 fibres (Specialty Materials) were coated by magnetron sputtering with a $100 \mathrm{~nm}$ titanium interlayer for improved bonding and a 500-nm-thin copper layer without breaking the vacuum to protect the titanium layer against oxygen. In a next step the pure copper matrix was deposited by electroplating. In a $\mathrm{CuSO}_{4}$ bath a $50-\mu \mathrm{m}$-thick $\mathrm{Cu}$ layer was grown on the fibres within 4 hours, resulting in a fibre volume fraction of $35 \%$. Uncoated and coated fibres were used for single fibre tensile tests at room temperature with a laser speckle extensometer for contact less strain measurements.

Heat treatment of coated single fibres at $550^{\circ} \mathrm{C}$ in vacuum with a very slow heating rate $\left(0.5 \mathrm{Kmin}^{-1}\right)$ served to reduce pores in the copper by outgassing of hydrogen. 
After heat treatment the coated single fibres for the composite were etched with an acid agent to remove surface oxide layers and subsequently packed in a $\mathrm{Cu}$ capsule (length $45 \mathrm{~mm}$, diameter $8 \mathrm{~mm}$ ), which was vacuum-sealed. The fibre reinforced zone had a diameter of $3.5 \mathrm{~mm}$. The composite was consolidated by hot-isostatic pressing (HIP) of these capsules at $650^{\circ} \mathrm{C}$ and $100 \mathrm{MPa}$ for $30 \mathrm{~min}$. Tensile test specimens were machined out of the composite capsules. The overall sample length was $44 \mathrm{~mm}$ with a parallel gauge length of $12 \mathrm{~mm}$ (Fig. 1). The diameter within the parallel gauge length varied between $3.5 \mathrm{~mm}$ and $4.5 \mathrm{~mm}$ in order to obtain fibre volume fractions in the range of $10 \%$ to $20 \%$. The threaded specimen ends were clamped by means of a hydraulic chuck. The clamp construction allowed to compensate for the temperature induced relaxation process in the copper threads and hence kept the clamping force at a sufficient level. The composite was tensile tested with a constant displacement rate of $1 \mathrm{~mm} / \mathrm{min}$. For high temperature tests the samples were inductively heated. A predominantly indirect heating characteristic was achieved by the combination of specimen, grips and induction coil geometry. A high portion of the inductively induced heat was generated in the nickel-based grips. Therefor heat conduction to the threaded ends was the dominant heat transfer mechanism. The homogeneity of the longitudinal temperature distribution within the gauge length has been verified by measurements of the specimen surface temperature (Fig. 2). The achieved temperature homogeneity and test conditions regarding to tractability (calibration) and alignment were compliant to tensile test standard ASTM-E21.

All determined values were compared with theoretical values calculated with the help of the rule of mixture [8]:

$$
\sigma_{c}=\sigma_{f} \cdot v_{f}+\sigma_{m} \cdot v_{m}
$$


where $\sigma$ is the stress, $v$ is the volume fraction, and subscripts $\mathrm{c}, \mathrm{f}$ and $\mathrm{m}$ denote the composite, fibre and matrix, respectively.

\section{Results}

Single fibre tensile tests were performed with uncoated (as received) SCS 6 fibres and with galvanically coated fibres with interlayer and copper matrix. The fibre volume content for these electroplated fibres was $35 \%$.

The mean ultimate tensile strength (UTS) of uncoated SiC fibres is $4450 \mathrm{MPa}$ at a strain of approximately $1 \%$. For the galvanically coated fibres (fibre volume fraction $35 \%$ ) the mean maximum stress reaches $1720 \mathrm{MPa}$ according to the rule of mixture. The fibres failed in a brittle manner at a strain value of $1 \%$.

Pure copper and composite specimens with $10 \%$ and $20 \%$ fibre volume fraction were tensile tested at room temperature. Fig. 3 summarises the stress strain curves of all samples. Pure copper shows a small elastic increase followed by a huge plastic deformation. The ultimate tensile strength of $200 \mathrm{MPa}$ was reached at $18 \%$ strain. The calculated Young's modulus is $110 \mathrm{GPa}$. With $10 \%$ fibre reinforcement the composite fracture behaviour changed from ductile to brittle. A nearly elastic increase up to almost $400 \mathrm{MPa}$ is followed by a brittle failure of the composites at a strain equal to the

maximum fibre strain of app. $1 \%$. The Young's modulus increased up to $142 \mathrm{GPa}$. The MMCs with $20 \%$ fibre volume fraction showed the same fracture behaviour. The composite samples failed at a strain of $1 \%$ in a brittle manner. The average ultimate tensile strength of three tested samples is $640 \mathrm{MPa}$ and for the Young's modulus $162 \mathrm{GPa}$ was determined. 
Additionally for a composite specimen with a fibre volume content of $20 \%$ the Young's modulus was determined in dependence of the temperature. Fig. 4 shows the average values of two tested samples, error bars indicate the standard error. The Young's modulus decreases with increasing temperature. Starting from $162 \mathrm{GPa}$ it reaches $113 \mathrm{GPa}$ at $550^{\circ} \mathrm{C}$. This value is comparable with pure copper at room temperature (110 GPa).

\section{Discussion}

The determined ultimate tensile strengths of pure copper and of the uncoated (as received) $\mathrm{SiC}$ fibre were used for calculation of the theoretical composite strength following the rule of mixture (Eq. 1). Fig. 5 shows a diagram of the UTS in dependence of the fibre volume fraction. The continuous line describes the rule of mixture. The symbols are average values of at least two tested samples. The standard error is indicated by error bars or is smaller than the symbol size. The UTS values for $10 \%$ and $20 \%$ of fibre volume fraction derive from composite specimens, the value for $35 \%$ arises from coated single fibres. Especially the UTS for composite specimens deviate from the rule of mixture, because the in situ strength of the galvanic copper matrix is lower than the UTS of the tested pure bulk copper used for calculation. Additional the galvanic copper matrix suffers some microstructural alterations during processing (outgasing, alloying with Ti, grain grow, tensile stress due to different coefficient of thermal expansion of $\mathrm{SiC}$ fibre and $\mathrm{Cu}$ matrix), which lead to changes in the mechanical properties. Also the fibre strength decreases during processing due to the reaction of titanium with the outer carbon rich layer of the fibres. If the composite is not heat 
treated, like for the galvanically coated single fibre with a fibre volume fraction of $35 \%$, the UTS agrees with the calculated value of the rule of mixture.

Since the fracture behaviour and the fracture areas are similar for all composite specimens, only the composite with $20 \%$ of fibre volume fraction will be considered further in the discussion. The fibre reinforcement of copper leads to a change of the fracture behaviour during tensile test in comparison to pure copper. The composite fails completely in a brittle manner. The strain was reduced from $18 \%$ (pure copper) to $1 \%$, while the ultimate tensile strength increased from $200 \mathrm{MPa}$ to $650 \mathrm{MPa}$. The fracture area is shown in Fig. 6. The fibres are homogeneously distributed within the matrix due to precoating of the fibres. Only a small amount of fibres are pulled-out. Most of the fibres show a very good bonding to the copper matrix. In Fig. 7 the middle of the specimen is shown with higher magnification and in BSE mode (back scattered electrons for materials contrast). The bonding between the SCS6 fibre and copper is excellent. Parts of the outer carbon layer of the SiC fibre (dark areas) adhere at the copper (bright areas) via the titanium carbide interlayer. Ti forms $\mathrm{TiC}$ with the outer carbon rich surface layer of the SCS6 fibre and the copper titanium alloy $\mathrm{Cu}_{4} \mathrm{Ti}$ was formed with the copper matrix [6], [7]. This leads to the very high bond strength between fibre and matrix. The weak point within the composite is not the fibre/matrix interface, but the SiC fibre itself. The SCS6 fibres failed due to its layered structure at the interface between the two outer carbon layers or between $\mathrm{SiC}$ and carbon layer.

\section{Conclusion}

The tensile strength of copper can be increased by reinforcement with $20 \%$ SCS6 fibres to almost $700 \mathrm{MPa}$. The Young's modulus reaches $162 \mathrm{GPa}$ for such a composite. This 
value decreases to $113 \mathrm{GPa}$ at $550^{\circ} \mathrm{C}$. The precoating of the fibres with a 100 -nm-thin titanium interlayer leads to a strong bonding between fibre and matrix. The weak point within the composite is the fibre itself due to its layered structure. Fracture area analyses after tensile tests show the failure of the fibres at the interface between the two outer carbon layers. Parts of the carbon layer still adhere at the copper. The load can be transported through the copper matrix to the SCS6 fibres via the TiC interlayer. The strain of fibre and matrix is the same, but the stress of fibres is higher due to higher modulus of elasticity of SiC. The fibres carry the load to a point, where the SCS 6 fibres fail.

\section{Acknowledgement}

The Authors would like to thank K.-H. Süss from EADS Ottobrunn for performing the hot isostatic pressing and T. Brendel from MTU Aero Engines Munich for carrying out the tensile tests of composite specimens.

A part of this work has been performed within the framework of the Integrated European Project „ExtreMat“ (contract NMP-CT-2004-500253) with financial support by the European Community. It only reflects the view of the authors and the European Community is not liable for any use of the information contained therein. 


\section{References}

[1] J. You, Design feasibility study of a divertor component reinforced with fibrous metal matrix composite laminate, Journal of Nuclear Materials 336 (2005) 97-109.

[2] J.H. You, H. Bolt, Overall mechanical properties of fiber-reinforced metal matrix composites for fusion applications, Journal of Nuclear Materials 305 (2002) 14-20.

[3] http://www.specmaterials.com/silicarbsite.htm.

[4] P.R. Smith, M.L. Gambone, D.S. Williams, D.I. Garner, Heat treatment effects on SiC fiber, Journal of Materials Science 33 (1998) 5855.

[5] A. Brendel, C. Popescu, C. Leyens, J. Woltersdorf, E. Pippel and H. Bolt, SiCfibre reinforced copper as heat sink material for fusion applications, Journal of Nuclear Materials 329-333 (2004) 804-808.

[6] A. Brendel, J. Woltersdorf, E. Pippel, H. Bolt, Titanium as coupling agent in SiC fibre reinforced copper matrix composites, Materials Chemistry and Physics 91 (2005) 116-123.

[7] A. Brendel, C. Popescu, H. Schurmann, H. Bolt, Interface modification of SiCfibre/copper matrix composites by applying a titanium interlayer, Surface \& Coatings Technology 200 (2005) 161- 164.

[8] Krishan K. Chawla, Composite Materials, Springer Verlag (2001). 


\section{Figure captions}

Fig. 1: Geometry of tensile test specimen

Fig. 2: Measurement of the specimen surface temperature with two thermocouples

Fig. 3: Stress/strain diagram of pure copper and composite material with $10 \%$ and $20 \%$ of fibre volume fraction

Fig. 4: Young's modulus of a composite material with $20 \%$ fibre content in comparison of pure copper in dependence of temperature.

Fig. 5: Ultimate tensile strength (UTS) at room temperature of SiC fibre, pure copper and composite material as a function of fibre volume fraction. The continuous line shows the calculated values following the rule of mixture (ROM).

Fig. 6: SEM image of the fracture area of a composite sample after tensile test at room temperature

Fig. 7: Image of back scattered electrons of the fracture area. Arrows indicate the carbon rich surface layer of the fibre (dark) which adheres at the copper matrix (bright). 
Figures

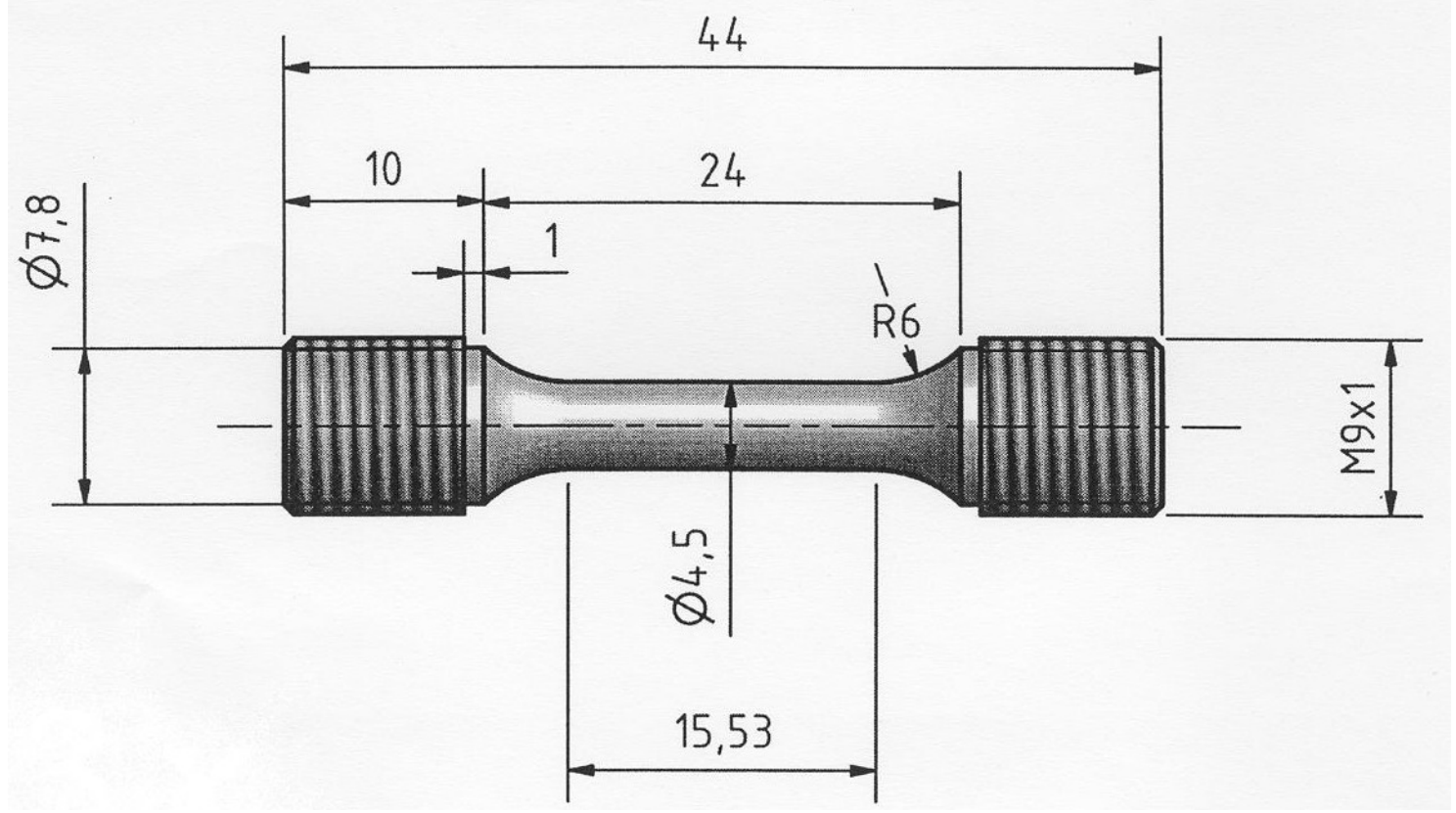

Fig. 1: Geometry of tensile test specimen 


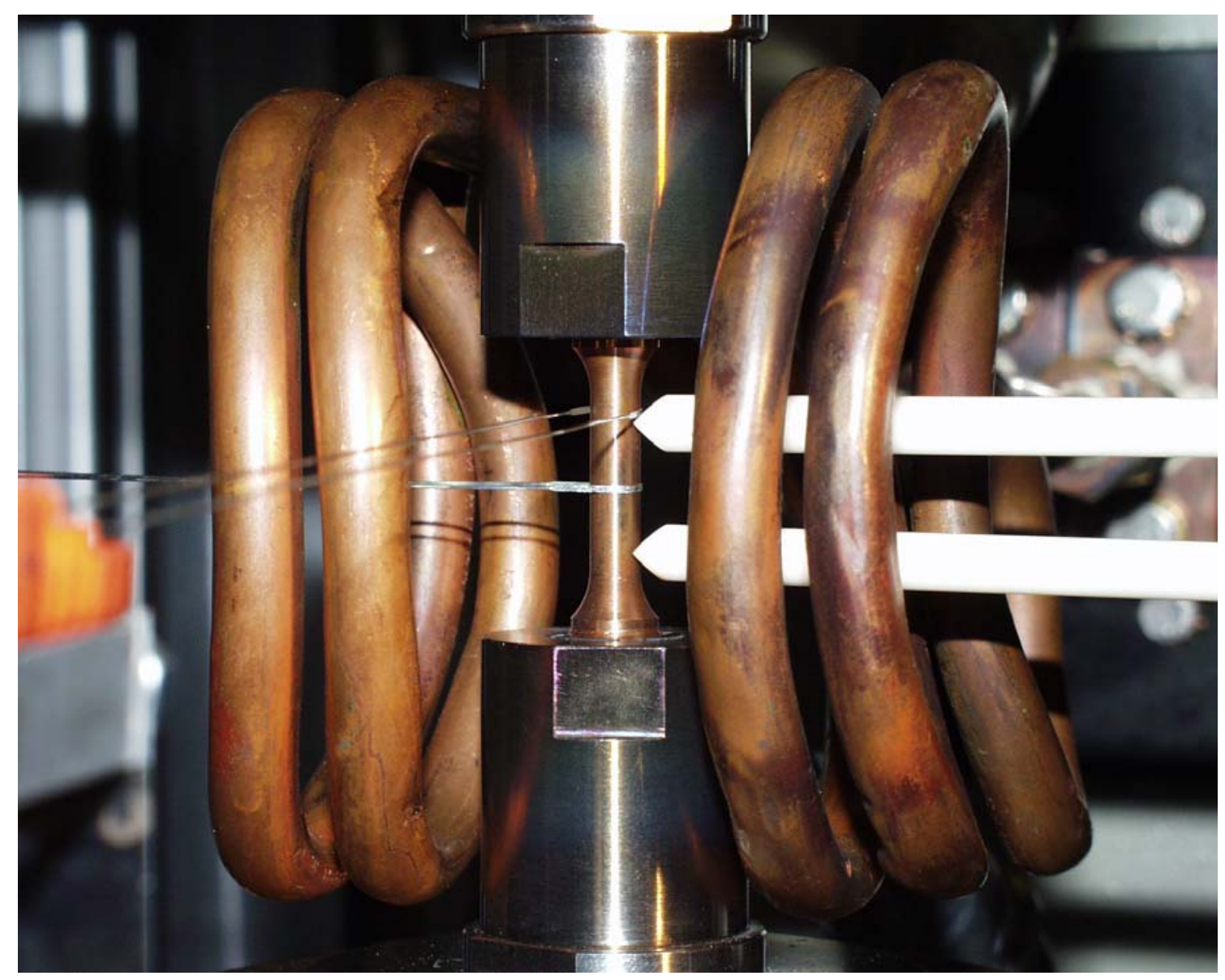

Fig. 2: Measurement of the specimen surface temperature with two thermocouples 


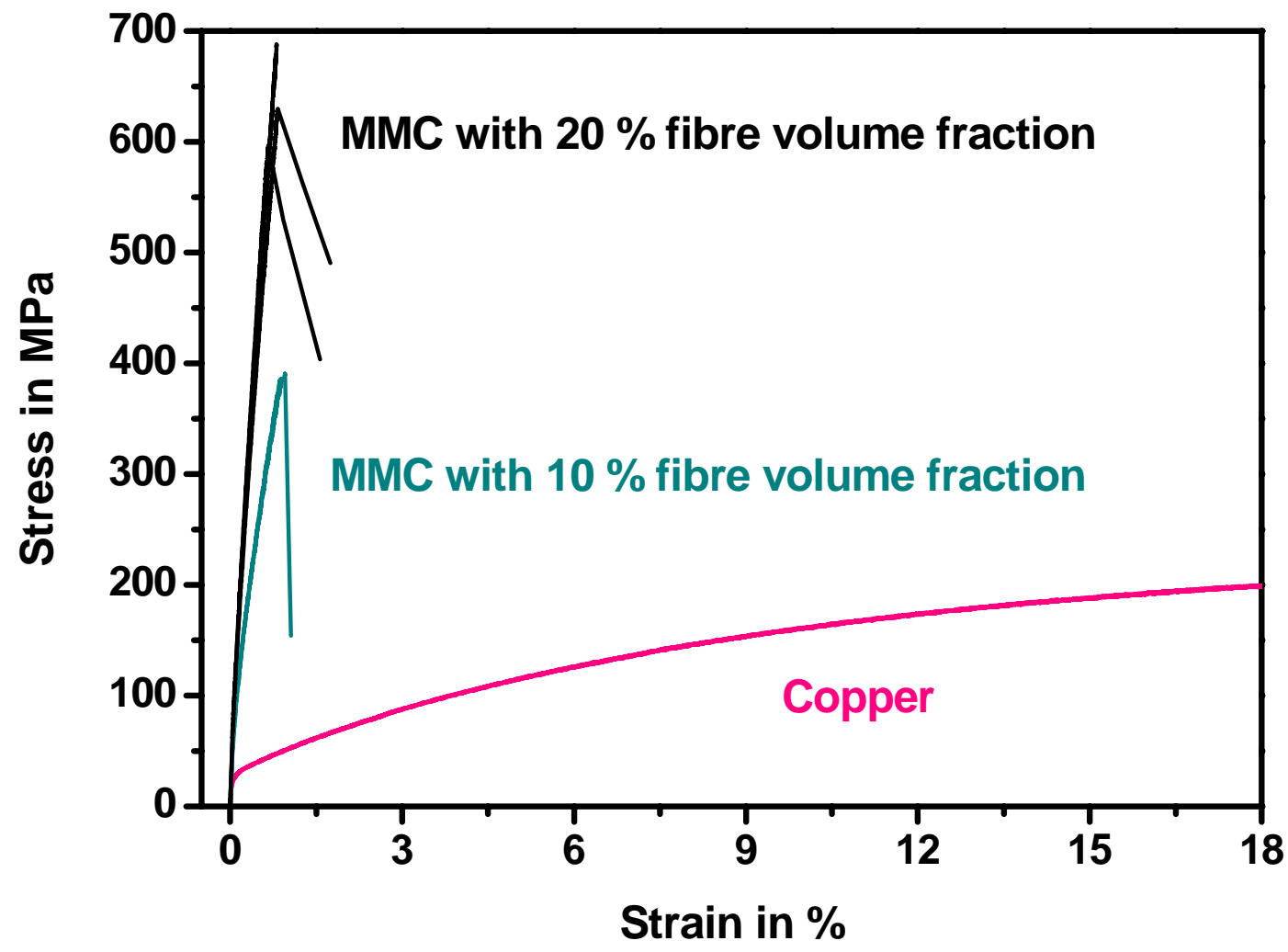

Fig. 3: Stress/strain diagram of pure copper and composite material with $10 \%$ and $20 \%$ of fibre volume fraction 


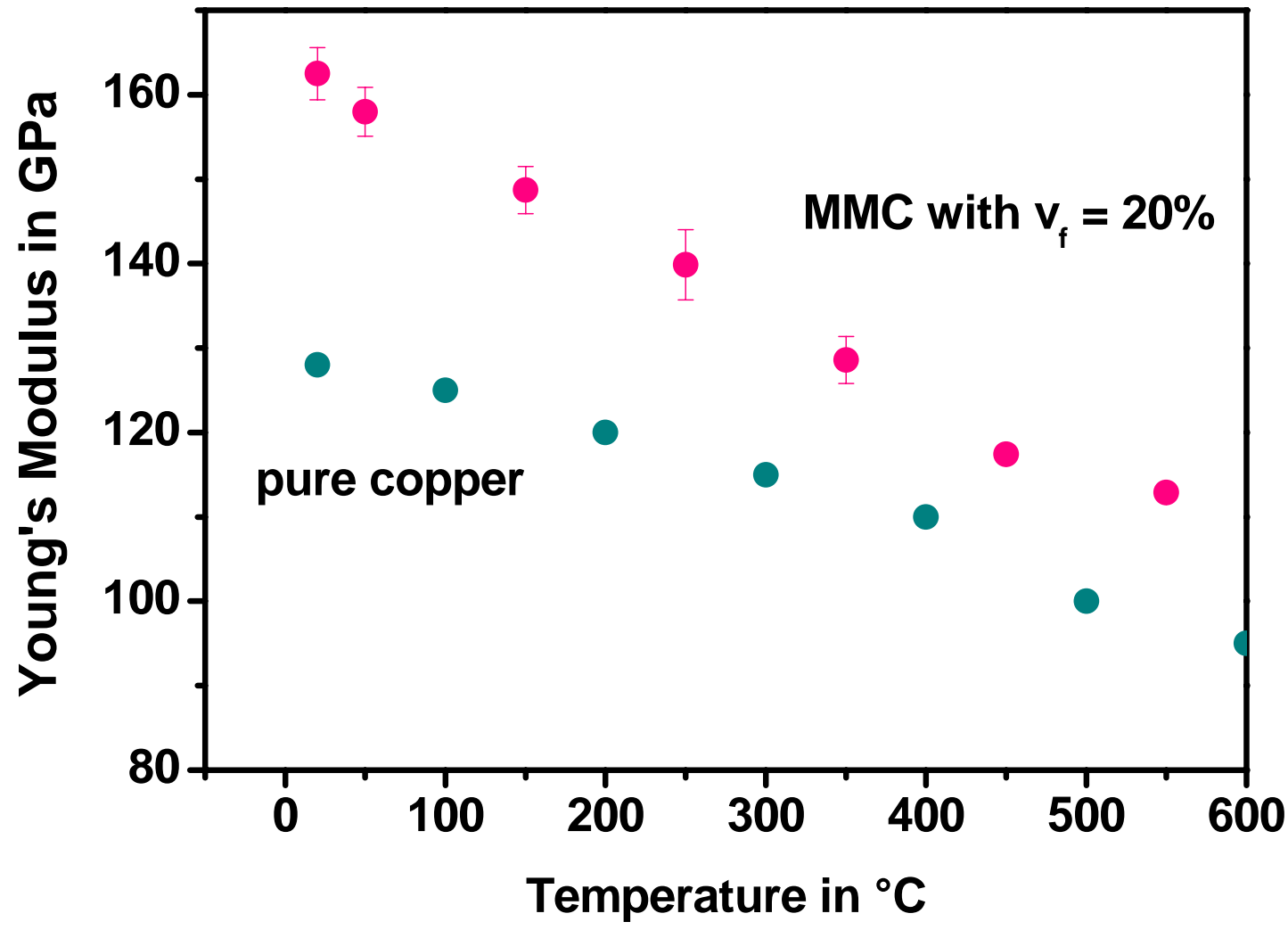

Fig. 4: Young's modulus of a composite material with $20 \%$ fibre content in comparison of pure copper in dependence of temperature. 


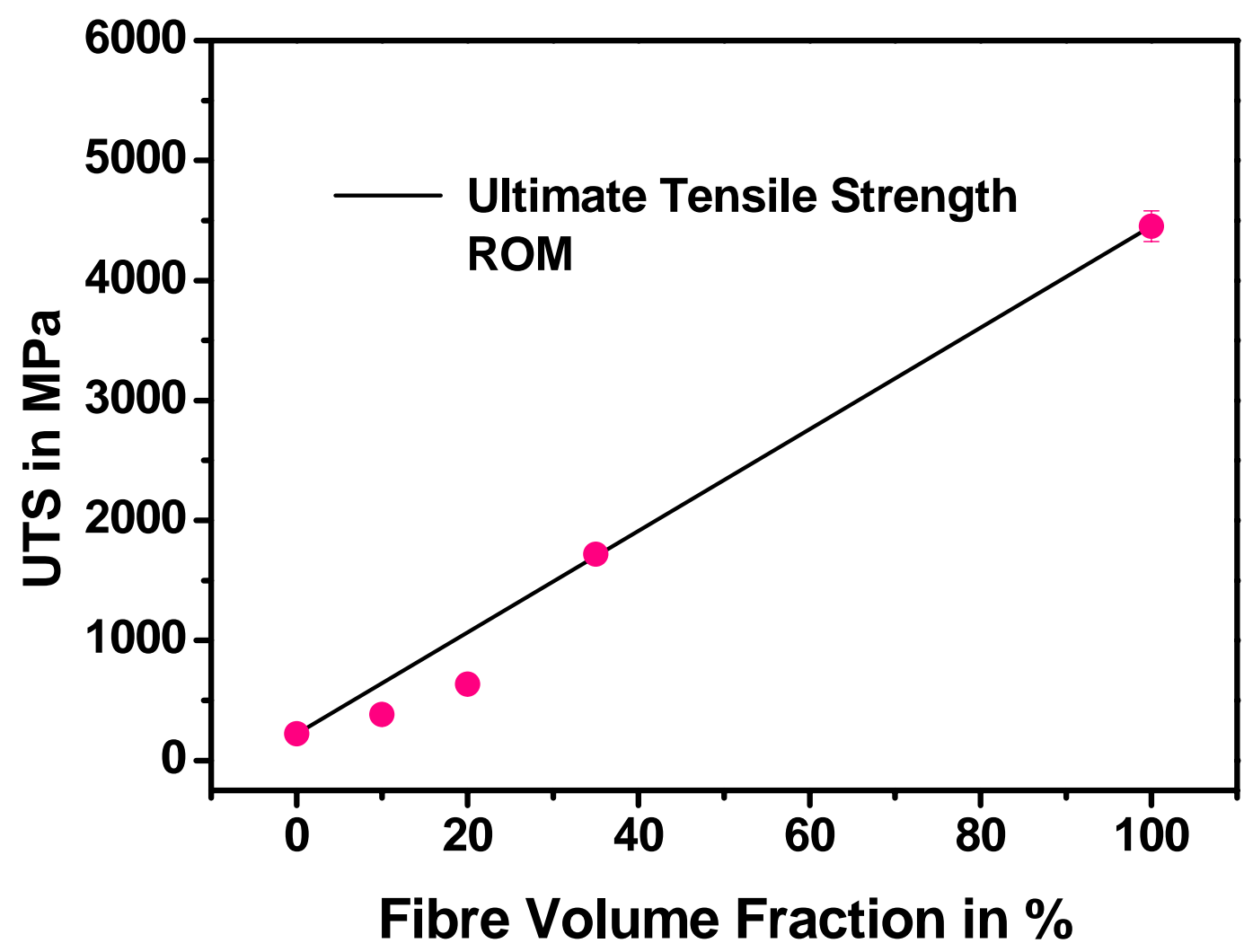

Fig. 5: Ultimate tensile strength (UTS) at room temperature of SiC fibre, pure copper and composite material as a function of fibre volume fraction. The continuous line shows the calculated values following the rule of mixture (ROM). 


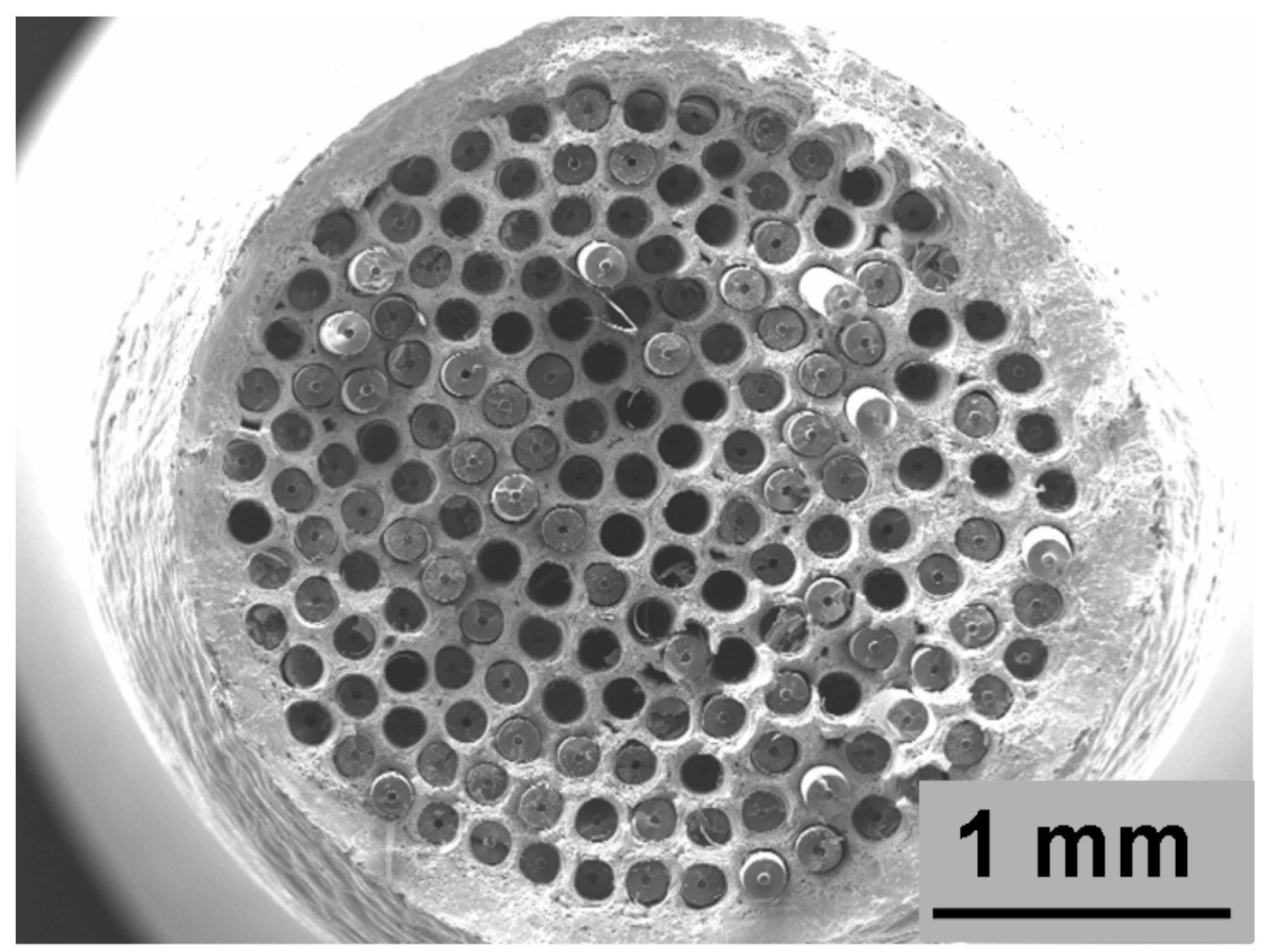

Fig. 6: SEM image of the fracture area of a composite sample after tensile test at room temperature 


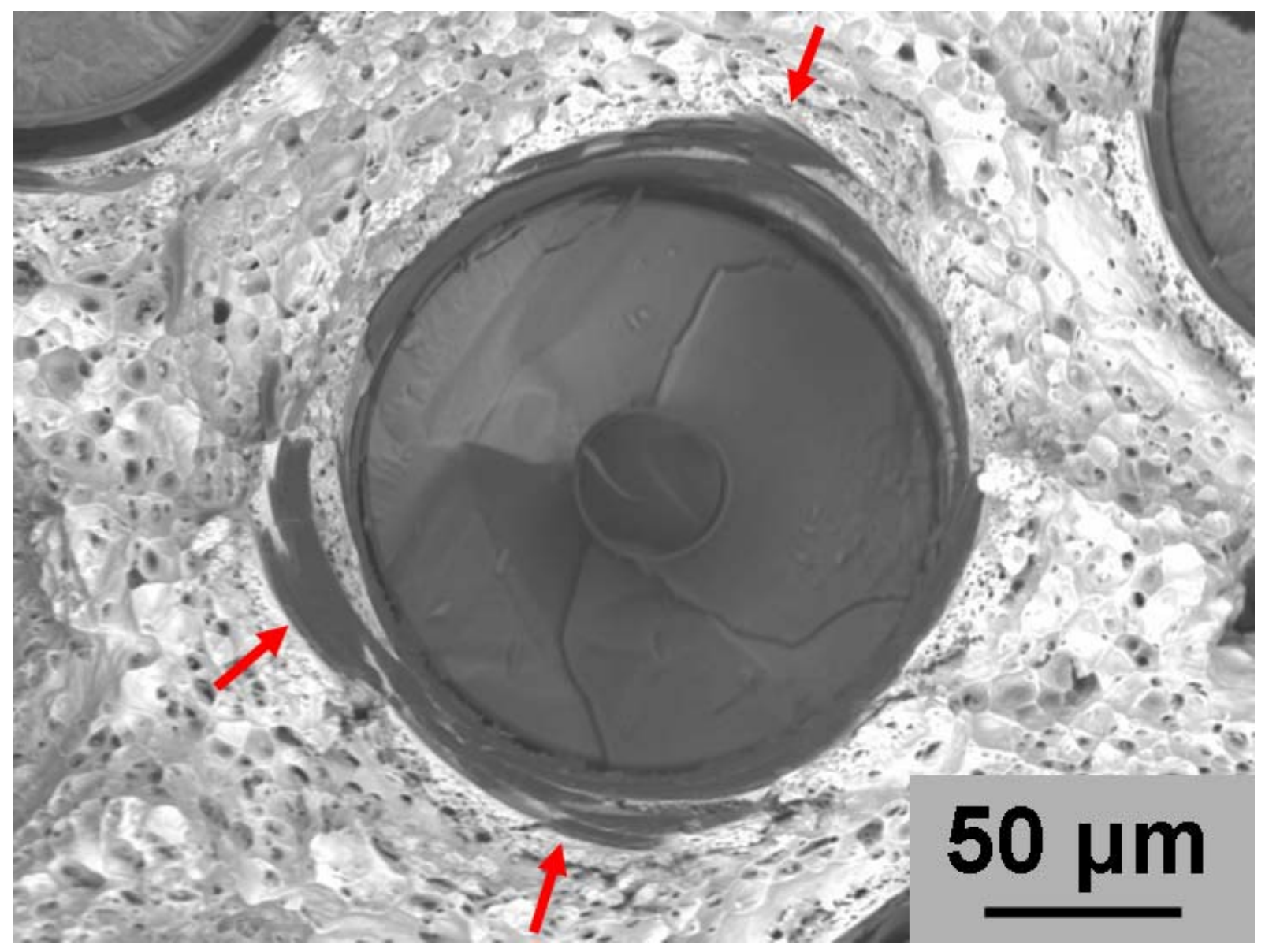

Fig. 7: Image of back scattered electrons of the fracture area. Arrows indicate the carbon rich surface layer of the fibre (dark) which adheres at the copper matrix (bright). 